\title{
Algumas Questões sobre a Avaliação do Portador de Deficiência Visual
}

\author{
Elcie F. Salzano Masini \\ Universidade de São Paulo (USP)
}

Uma análise da bibliografia especializada sobre o deficiente visual revelou que pesquisas sobre seu desenvolvimento e sua aprendizagem têm sido feitas através de padrões do vidente. Este trabalho, a partir de dados dessas pesquisas, levanta alguns pontos para que os que lidam com a educação do deficiente visual reflitam sobre as implicações de fazer avaliações de cegos e portadores de visão subnormal usando o referencial do vidente. É um convite para que se pense em caminhos para conhecer o deficiente visual a partir de seu próprio referencial.

\section{Introdução}

A análise da bibliografia especializada sobre o portador de deficiência visual mostra que seu desenvolvimento e sua aprendizagem têm sido definidos (ver resumo de pesquisas sobre o deficiente visual no Anexo deste artigo) a partir de padrões adotados para os videntes. Verifica-se, com certa surpresa, que, nos instrumentos e propostas examinadas, o conhecer esperado na educação do deficiente visual tem como pressuposto o ver, e que, portanto, não se leva em conta as diferenças de percepção do deficiente visual e do vidente. A desconsideração dos autores a essas diferenças pode-se supor que tenha sido determinada pela desatenção à predominância da visão ou àquilo que ficou encoberto pela familiaridade, oculto pelo hábito, linguagem e senso comum, em uma cultura de videntes. 
Assim o deficiente visual permanece oculto ao ser apresentado pela percepção unidimensional da visão.

No mundo dos videntes, como não poderia deixar de ser, a fala que se impõe é a sua. Seria absurdo negar este fato. Antes, ele deve ser considerado para que se possa identificar os conceitos, os valores e as definições do senso comum ditados pelo sentido da visão, pois este, quando utilizado como referencial na avaliação do deficiente visual,não permite conhecê-lo, mas tão-somente compará-lo com os que enxergam.

Com a preocupação de encontrar um caminho para saber a respeito do deficiente visual, suas características, seu desenvolvimento e sua aprendizagem, este trabalho apresenta alguns pontos sobre a avaliação daquele que não dispõe da visão como sentido dominante, para reflexão dos que lidam com sua educação.

\section{O que é avaliar?}

No uso cotidiano, o termo avaliar é entendido de diferentes maneiras, tais como: determinar a valia ou valor, calcular, computar, apreciar, considerar. O mesmo ocorre no campo profissional, quer do educador, quer do psicólogo, permanecendo certa obscuridade no seu significado. Se um desses profissionais afirma "Estou fazendo avaliação desta criança", há ainda muito a ser esclarecido. O significado de avaliação diverge de acordo com o ponto de vista em que o profissional se coloca. As diferentes fundamentações (de uma linha comportamental, cognitivista, psicanalitica, institucional, fenomenológica, etc.) dão margem a controvérsias quanto a objetivos e recursos.

Quer o profissional tenha clareza, quer não, um embasamento filosófico de ciência permeia seu enfoque de trabalho. Dessa forma, a delimitação que ele irá fazer do alcance da avaliação realizada (que envolve consciência das possibilidades e dos limites da ação desenvolvida e daquilo que se poderá saber através dos recursos util izados) implica o conhecimento desse embasamento filosófico.

Para falar de instrumentos de avaliação do deficiente visual cabe, portanto, anteriormente, uma breve referência a esse embasamento. Para 
isso será retomada a visão de Kaplan (1964) sobre os pesquisadores das ciências do comportamento. Segundo este autor, temos, a grosso modo, a seguinte subdivisão:

1. Aqueles que se propõem a alcançar o significado da ação, ou seja, do que é manifesto, segundo uma teoria ou explicação particular. Diz respeito ao comportamento observável ou a um produto do sujeito.

2. Aqueles que se propõem a alcançar o significado do ato, ou seja, o que ele representa para o agente ou para aquele com quem interage, a partir da interpretação de uma particular teoria. Diz respeito ao significado do agente ou ao processo de sua ação, segundo uma teoria.

A primeira explicação depende, para sua interpretação, de um referencial exterior ao sujeito avaliado; a segunda parte do referencial do sujeito (referencial semântico) para fazer a interpretação baseada num referencial teórico.

Considerando a classificação de Kaplan, a seguir serão contemplados aspectos da avaliação psicológica e da avaliação educacional do portador de deficiência visual.

AVALIAÇÃO PSICOLÓGICA DO DEFICIENTE VISUAL

Na primeira posição (lidando apenas com o significado da ação), poderiam ser colocados os psicólogos da linha comportamental que se opõem a explicações baseadas em motivos. Esses psicólogos, na busca de objetividade, seguindo com rigor os modelos das ciências naturais, têm deixado de lado questões como o significado do ato, argumentando que para chegarse a ele é necessário recorrer a relatos, interpretações pessoais e, portanto, a dados subjetivos que escapam à verificação objetiva.

Na segunda posição poderiam ser citados vários psicólogos de correntes psicanalistas ou psicogenéticas. Estes buscam uma sistematização que possibilite compreender o ser humano, sem, porém, se restringir a uma metodologia retirada das ciências naturais. Buscam explicar o significado da ação, mas lidam também com o significado do ato, isto é, com o que o indivíduo percebe de sua própria ação. Partem de significados trazidos pelo sujeito para daí levantarem 
hipóteses que permitam a compreensão de sua ação. Essas hipóteses se fundamentam numa teoria psicanalitica ou psicogenética, através da qual o psicólogo busca maior objetividade. Poder-se-ia considerar este processo de levantamento de hipóteses como um momento em que o psicólogo se aproxima da metodologia das ciências naturais: para buscar as causas dos fenômenos, o psicólogo procura explicar a causalidade psicológica da ação de seu cliente. Posteriormente, através de uma explanação verbal, retorna ao diálogo, procurando auxiliar o cliente na sua autocompreensão, ao interpretaros significados que ele inicialmente trouxe sob o enfoque de uma teoria explicativa. Dessa forma, os psicólogos de corrente psicanalista ou psicogenética em alguns momentos lidam com relatos e percepções, em outros momentos, com dados provindos de uma teoria, teoria essa que se propõe a encontrar e a sistematizar determinantes do comportamento humano. Para deixar rnais claro o exposto, no que diz respeito à questão da avaliação, são apresentados dois exemplos.

Um exemplo de significado da ação em avaliação

(Retirado da Proposta Curricular para Deficientes Visuais do Centro Nacional de Educação Especial (CENESP), MEC, 1979, p.39).

\begin{tabular}{|c|c|c|c|c|c|c|c|}
\hline \multicolumn{8}{|l|}{ Objetivo: participação } \\
\hline & \multicolumn{7}{|c|}{ Dia - Mês } \\
\hline Comportamento observado & 3 & 6 & 10 & 12 & 19 & 24 & 26 \\
\hline Concentrou a atenção & $\mathrm{X}$ & & $\mathrm{X}$ & & & & \\
\hline Fixou ouvido em quem fala & & $\mathrm{X}$ & & & & & \\
\hline Formulou pergunta & & & $\mathrm{X}$ & & & & \\
\hline Manipulou material usado na aula & & & & $X$ & $\mathrm{X}$ & $X$ & $X$ \\
\hline Expressou-se oralmente & & & & $\mathrm{X}$ & & $\mathrm{X}$ & $\mathrm{X}$ \\
\hline Pediu esclarecimento sobre a tarefa & & & & $\mathrm{X}$ & & & \\
\hline Relatou tarefa da vida familiar & & $\mathrm{X}$ & & $\mathrm{X}$ & & $\mathrm{X}$ & \\
\hline
\end{tabular}

- O psicólogo observa e registra se houve presença de comportamento. 
Um exemplo de significado de ação e do ato

(Rclirado do artigo de Gottesman, "Stage Development of Blind Children: a Piagctian View". In: The Newoutlook. March 1976, v.70, p.3).

Avaliação das explicações dadas por crianças cegas e videntes ao lidar com objetos e argila, para estudo da "conservação" de massa, peso e volume:

Gottesman introduzia o material nas mãos das crianças cegas e videntes, dizendo: "Agora eu colocarei em suas mãos algo para você sentir. Veja se você sabe o que é". Cada criança fazia as provas e era questionada individualmente em cada situação ao ser solicitada a predizer/julgar/explicar. As crianças realizavam as tarefas e o psicólogo conversava sobre o que haviam feito, buscando compreender sua concepção e as transformações de suas concepções através de comunicações e diálogos apropriados à criança. As explicações eram categorizadas, tendo como referência a Teoria de Piaget. Ao procurar compreender a resposta da criança, o psicólogo buscava o significado do ato; ao categorizar suas explicações a partir do referencial de Piaget, buscava o significado da ação.

Nas ciências físicas essa distinção entre ato e ação não tem lugar. Nas ciências do comportamento, e até certo ponto nas ciências biológicas, reconhece-se que os atos possuem sentido, isto é, constituem uma ação dirigida a um fim. Em outras palavras, quer isso dizer que todo significado de um ato é finalistico, isto é, se opõe a um ato gratuito. Isso tudo parece óbvio quando se fala da avaliação psicológica de uma criança ou adolescente. Parece absurdo repisar a importância do não se satisfazer com uma explicação da ação (ainda que bem fundamentada numa teoria), deixando de lado a busca do significado do ato. No entanto, na prática de trabalho, nem sempre isso fica tão óbvio. Vejamos, pois, para ilustrar esta afirmação, os instrumentos que têm sido oferecidos para a avaliação individual do deficiente visual e como têm sido utilizados.

Vamos tomar um exemplo de nossa realidade. Amiralian (1986) pesquisou a cognição do cego congênito, utilizando para a avaliação o WISC Verbal e o BLAT (Blind learning aptitude test, de Newland, 1971). Seus 
sujeitos foram crianças de 6 a 15 anos que freqüentavam do pré-escolar à $5^{\text {a }}$ série. Reiterando a afirmação de Bauman (apud Sabatino, 1979) de que o teste individual de inteligênciastandartizado rnais usado para crianças deficientes visuais é a escala verbal de Weschler (WISC Verbal), Amiralian apresenta as seguintes justificativas para a escolha desse instrumento:

1. Ser o teste extensivamente citado pelos vários pesquisadores que demonstraram suavalidade para a avaliação do desenvolvimento intelectual de sujeitos cegos.

2. Possibilitar uma análise qualitativa do papel obtido a partir dos resultados para cada subteste, o que permite identificar dificuldades comuns às crianças cegas.

A escolha do BLAT para o estudo do desempenho foi feita por ser um teste criado especialmente para a avaliação de sujeitos cegos e por estar livre, de acordo com o autor, de influências culturais.

Amiralian aplicou cinco subtestes do WISC Verbal: Informação, Compreensão, Aritmética, Números e Semelhanças. A avaliação foi feita segundo normas padronizadas (tradução da Cepa). O BLAT foi aplicado e avaliado segundo as normas estabelecidas pelo seu autor. $\mathrm{O}$ material do BLAT utilizado para a pesquisa foi uma cópia do modelo americano, feito na Fundação para o Livro do Cego no Brasil (FLCB), hoje denominada Fundação Dorina Gouvea Nowill. Algumas diferenças ocorreram nessa tiragem. Foi feito um teste com um grupo de cegos, a fim de constatar se essas diferenças poderiam produzir modificações que interferissem nos resultados. Concluiu-se que as diferenças (no papel e tamanho dos pontos em relevo) não interferiram na compreensão do modelo. A avaliação do desenvolvimento cognitivo foi feita a partir dos resultados registrados nos protocolos dos itens do WISC Verbal e do BLAT. A relação entre a avaliação verbal e a de execução foi analisada pelos QIs obtidos a partir da aplicação e da avaliação dos dois testes. Os resultados foram estudados a partir de uma análise estatística, utilizando os seguintes procedimentos: Prova de Kruskal-Wallis e correlação de Postos de Spearman. A análise dos subtestes do WISC foi realizada a partir da média e do desvio-padrão dos pontos ponderados para a população geral e para os grupos por série escolar e 
idade cronológica. O mesmo procedimento foi adotado para o BLAT, realizando-se a partir daí o estudo da relação entre desempenho verbal e de execução. Os resultados foram rnais elevados no BLAT do que no WISC.

Os resultados do BLAT (de acordo com o próprio autor) eqüivalem principalmente a uma avaliação dos processos psicológicos básicos utilizados na aprendizagem, enquanto os do WISC expressam os conhecimentos adquiridos pelo sujeito, isto é, o produto da aprendizagem. Diante disso, cabe perguntar: E possível esta diferenciação? Referir-se aos resultados do BLAT como avaliativos dos processos utilizados na aprendizagem e os do WISC como avaliativos dos produtos de aprendizagem é uma forma de desvincular aquilo que o indivíduo faz (produto ou ação) daquele processo que possibilita que ele faça (sua compreensão do que o leva à ação, isto é, o ato).

A utilização de instrumentos (testes e tratamento estatístico) para a avaliação do aspecto cognitivo do deficiente visual, sem utilização de outros recursos, ilustra uma postura psicológica voltada para o significado da ação. Como afirma Kapperman (apud Sabatino, 1979), testar o QI de crianças cegas é, na melhor das hipóteses, uma questão duvidosa, pela pobreza de instrumentos disponíveis. A maior parte dos instrumentos para esse propósito são adaptações de projetos originais para pessoas videntes, ficando implícita nessa utilização de instrumentos a crença de que a criança deficiente visual está exposta às mesmas experiências culturais da criança vidente. Isso, porém, não parece ocorrer, pois a exploração do ambiente pelo deficiente visual é rnais limitada e depende das condições que lhe são oferecidas e, de um modo geral, ela não passa pelas mesmas experiências do vidente.

Um outro ponto que constitui dificuldade na adaptação de instrumentos para a avaliação do deficiente visual é sua validade para uma população visualmente deficiente. Devido à facilidade de se encontrar uma grande população nas escolas residenciais, tem-se recorrido a esses portadores de deficiência visual. Isso leva a uma amostra enviesada, devido ao fato de suas experiências serem circunscritas às mesmas condições físicas e educacionais. 
Outro aspecto a ser considerado diz respeito às limitações do deficiente visual a situações às quais ele não tem acesso (experiências de cor/movimentos de objetos a distância, etc). Isso leva à excessiva ênfase na escala verbal em certos itens de avaliação.

Atualmente não há teste de inteligência bem projetado ou organizado, e bem estandardizado, para deficientes visuais. Segundo Classen (1974), os testes puramente verbais não serão fidedignos, enquanto os ambientes de casa se mostrarem rnais restritivos para os cegos do que para os videntes.

Os testes de inteligência utilizados com deficientes visuais no Brasil são, como já foi dito, o Wechler Verbal (WISC), o Ohwaki Kohs - cubos táteis (avaliação a partir de 6 anos de idade) - e o Teste de Inteligência Williams, para crianças com cegueira e visão subnormal (England), traduzido por Maria Lúcia Amiralian e distribuído pela FLCB.

Outro teste projetado para uso com deficientes visuais, de origem americana, e adaptado para população brasileira, é a Escala de Ballard e Barraga (1971). Na construção dessa escala, esses autores listaram seções e subtestes de instrumentos bem conhecidos, que são usados para avaliar o nível de funcionamento de crianças portadoras de visão subnormal na pré-escola. A título de ilustração, apontamos a seguir algumas habilidades incluídas na escala e os instrumentos de onde foram retirados.

\begin{tabular}{|l|l|}
\hline Habilidades medidas & Instrumentos dos quais foram retirados os itens \\
\hline $\begin{array}{l}\text {. Memória imediata } \\
\text { Associação }\end{array}$ & . Teste Illinois de Habilidade Psicolinguistica \\
. Pensamento lógico & . Escala Stanford Binet \\
. Intelligency & \\
. Discriminação & \\
. Relação espacial & \\
. Psicomotricidade & . Arthur Point Scale of Performance Test \\
. Raciocínio dedutivo & - Hiskey Nebraska of Hearing Aptitude \\
Raciocínio indutivo & . Columbia Mental Maturity Scale \\
- Generalização & \\
- Imitação & \\
. Atenção imediata & \\
. Desenvolvimento da linguagem & \\
\hline
\end{tabular}


Considerando que esses instrumentos foram, originalmente, organizados para pessoas videntes, as mesmas restrições feitas por Kapperman, já citadas anteriormente, aplicam-se a essa escala.

Um outro ponto que cabe ainda assinalar é que esses instrumentos, pela forma de aplicação e de registro, em geral, só podem ser empregados na avaliação do deficiente visual como ferramentas clínicas.

Como ficou exposto, o estudo do aspecto cognitivo e de aquisição de habilidades, através do uso de testes, constitui limitação por restringir-se ao significado manifesto, interpretado a partir de quadros referenciais (significado da ação). O material apresenta situações pré-delimitadas e preestabelecidas; não leva em conta o indivíduo no seu dinamismo, desconsiderando sua experiência e as implicações afetivas e sociais.

Qualquer profissional, ao se referir à avaliação psicológica de um indivíduo, faz menção à necessidade de conhecimento de suas condições intelectuais, perceptivas, motoras e de ajustamento afetivo-emocional. $\mathrm{Na}$ literatura especializada referente à avaliação do deficiente visual, fica assinalada a importância de se estar atento às reações emocionais do deficiente visual. Não há, contudo, citação de estudos sobre qualquer um desses aspectos, quando se coloca um portador de deficiência visual diante de provas pouco apropriadas para mostrar sua maneira de perceber e de elaborar a partir daí.

Ficam, assim, assinaladas lacunas sobre a avaliação do deficiente visual, no que diz respeito a instrumentos ou a situações que permitam conhecê-lo na sua maneira própria de perceber, sentir e organizar-se no mundo que o rodeia. Como a avaliação psicológica constitui um recurso fundamental para a orientação educacional do deficiente visual, faz-se premente uma reflexão sobre essa questão. Só numa atitude pioneira de investigação é que o psicólogo poderá pensar nos caminhos apropriados para conhecer o deficiente visual. Isso requer que ele deixe de se satisfazer com explicações ou interpretações calcadas em teorias e pesquisas baseadas no visual e que busque o referencial perceptual do deficiente visual como ponto de partida. 
AVALIAÇÃO PEDAGÓGICA DO DEFICIENTE VISUAL

Esta é a avaliação que cabe ao professor e é feita através de um longo processo. Só a partir dos dados obtidos e coordenando-os com as informações do oftalmologista é possível traçar um plano educacional apropriado ao aluno deficiente visual.

Vale para o professor o que ficou dito antes sobre o profissional em psicologia. Se um professor faz a correção, baseado nas respostas dadas pelo aluno, estará avaliando a partir do "significado da ação". Se o professor faz a correção analisando como o aluno procedeu para responder estará voltado para o processo, portanto, estará avaliando voltado para o "significado do ato".

Para traçar um procedimento de avaliação, o professor precisa ter claro seu objetivo e a maneira de poder atingi-lo: saber se a meta da avaliação é determinar o nível de funcionamento (para o planejamento de um programa educacional apropriado ao deficiente visual) ou prognosticar suas condições de acompanhar um programa de classe comum. No primeiro caso, a avaliação estará voltada para o progresso individual (avaliação por critério); no segundo caso (avaliação por norma), para comparação dos resultados do indivíduo deficiente visual em relação a um grupo, no caso, a classe. Ambas são importantes para uma avaliação completa.

Uma questão que merece atenção inicialmente é a que diz respeito aos critérios de avaliação do cego e dos portadores de visão subnormal. Servem, pois, como ponto de partida duas perguntas: Serão diferentes os tipos de capacidade de aprendizagem do cego e das pessoas que têm alguma visão residual? Quais os aspectos diferentes e como poderão ser avaliados?

Como já vimos, quanto rnais completa a avaliação mais se terá condições para uma programação que propicie desenvolvimento, aprendizagem e preparo para a integração social.

Para isso, no caso do deficiente visual, é necessária uma abordagem adequada, não só do que se refere a comportamentos e habilidades acadêmicas, como também dos aspectos funcionais de seus modos de: 
— realizar as atividades pessoais;

— relacionar-se com outras pessoas;

- usar seu corpo e seus sentidos;

— desempenhar-se na sala de aula;

— usar habilidades que lhe permitam participar da sociedade rnais amplamente.

O primeiro ponto que requer atenção, após a definição clara dos objetivos, diz respeito aos instrumentos e às medidas a serem utilizados. Para que se possa realmente ter um quadro das possibilidades do deficiente visual, em seus aspectos acadêmicos e funcionais, é necessário antes de rnais nada refletir sobre os recursos oferecidos, considerando-se, no mínimo, os itens seguintes:

- Perguntar até onde são adaptações de material organizado para avaliar o mundo do vidente.

- Analisar instrumentos e selecionar os que permitam avaliar habilidades e comportamentos provenientes de uma organização que não se baseie no visual.

Enquanto se realiza a avaliação, é necessário aprofundá-la também através de uma análise que esclareça sobre o significado do nível obtido. Nesse sentido, o que se busca saber são os dados sobre a experiência desenvolvida pelo deficiente visual, isto é, o quanto ela propicia, em seus vários aspectos, um crescimento de autonomia; o quanto ela é deficitária nesse sentido; se há dificuldades que interferem além da deficiência visual e que requerem um parecer do neurologista, ou de outro especialista; como está seu processo de aprendizagem, localizando suas facilidades e problemas.

Como já dissemos, para uma programação educacional, o professor necessita complementar sua avaliação pedagógica com outras informações, tais como as que seguem:

- Informações do exame oftalmológico e optométrico sobre a extensão das condições da visão e das partes do olho e da visão afetadas; 
sobre as condições da pessoa se esforçar para enxergar e o cansaço resultante daí (para saber sobre o material quanto ao tamanho e ao tipo a ser usado pelo professor em sala de aula).

- Informações sobre comportamento funcional e níveis de desempenho. A obtenção destas informações requer um contato com o deficiente visual em ambientes familiares, onde ele se sinta mais à vontade para mostrar o que sabe e o que não sabe. O professor poderá obter esses dados observando a criança em situações informais, no que diz respeito à sua mobilidade em seu ambiente pessoal e no seu relacionamento cotidiano. Isso pode ser feito em diferentes situações no ambiente escolar: na lanchonete ou no refeitório; na movimentação pelo prédio escolar; na participação em sala de aula; no uso de materiais pessoais e escolares; na forma de relacionar-se com pessoas e ambientes.

\section{Avaliação e educação do deficiente visual: implicações}

O que pesquisas e estudos analisados assinalaram, de um modo geral (apesar das controvérsias em seus resultados e explicações), é que o atraso encontrado no desenvolvimento dos deficientes visuais deve-se:

1. aos aspectos perceptuais ou representacionais (que são caracterizados pelo empobrecimento de imagens), e não a dificuldades situadas no aspecto operacional;

2. à utilização de níveis cognitivos não apropriados à compreensão e à organização das situações (fazendo o deficiente visual aproximação de problemas conceituais abstratos, através de um nível concreto e funcional; aproximação de tarefas que envolvem representações ou imagens, através de níveis conceituais), num esforço de compensar déficits;

3. às condições educacionais (familiares e escolares), que não supriam as necessidades de desenvolvimento dos deficientes visuais e nem forneciam oportunidades para maximizar suas possibilidades, e não aos limites provenientes da deficiência visual. 
Um outro aspecto frisado no material analisado refere-se à inadequação dos recursos diagnósticos utilizados com o deficiente visual, e que se manifesta em:

1. impropriedade na utilização dos testes verbais de inteligência, elaborados para videntes e usados para cegos;

2. dificuldades de adaptação de testes de execução para avaliação dos deficientes visuais.

A esses dois itens levantados, cabe acrescentar um terceiro:

3. impropriedade dos critérios (para conhecimento da experiência do sujeito e sua formação simbólica), cujo referencial é o da comparação entre deficientes visuais e videntes.

Como ilustração do item 3, são retomados a seguir alguns dados encontrados por Mephart, Mephart e Schwartz (1974), assinalando déficit das crianças deficientes visuais na descrição das pessoas e do ambiente, por elas se referirem a menos partes do corpo dos amigos. Esquecem esses autores, no entanto, que na cultura ocidental as partes do corpo são características percebidas visualmente. Poder-se-ia afirmar que as imagens pobres ou as concepções imprecisas dos deficientes visuais, encontradas por esses autores, estão reiterando simplesmente que a descrição do ambiente se faz habitualmente pelo visual. As conclusões de Foster (1977), de que as imagens das crianças cegas são basicamente reprodutivas, isto é, permanecem estáticas, é uma outra ilustração disto; a ausência de referencial perceptivo próprio (tátil, auditivo, olfativo, cinestésico) faz com que a criança cega fique presa estaticamente a informações recebidas, repetindo-as, impedida de com elas operar.

Os dados e as conclusões evidenciaram que pouco se sabe sobre o deficiente visual. O "empobrecimento de imagens" estará revelando características de sua percepção ou ausência de recursos para conhecimento dessas características? "A utilização de níveis cognitivos não apropriados à compreensão e organização das situações" estará se referindo a deficiências do deficiente visual ou das condições educacionais que não propiciaram a ele essa apropriação? 
Por outro lado, as conclusões enfatizaram a inadequação dos recursos para a avaliação do deficiente visual.

No entanto, os autores das pesquisas analisadas, de um modo geral, em suas conclusões, apresentaram sugestões para a educação do deficiente visual, chamando a atenção para a relação do desenvolvimento do deficiente visual com suas condições educacionais. É importante lembrar que Gottesman (Ver Anexo), cujos estudos não apontam diferenças entre os deficientes visuais e os videntes, caracteriza os sujeitos de seus experimentos como bem ajustados e integrados, bem aceitos pelos familiares, tendo sido tratados primeiro como crianças e depois como portadores de deficiência. $\mathrm{O}$ autor refere-se ao grau de liberdade dado pelos pais como fator crucial para seu bemestar. Gottesman chama, porém, a atenção para o fato de que seus sujeitos constituem um grupo selecionado. Suas conclusões exatamente por isso parecem importantes, pois ilustram que, quando as condições educacionais são apropriadas, o deficiente visual desenvolve suas possibilidades.

De forma bastante simplificada, de tudo o que ficou exposto, poderemos dizer: professor ou psicólogo estarão iniciando um caminho para compreender o deficiente visual no seu pensar.sentir e agir, quando questionarem a avaliação voltada para o "significado da ação" (comportamento observável ou resposta), e buscarem uma avaliação que considere também o "significado do ato" (o que significa para o agente sua ação). Ou em outras palavras, quando questionarem a avaliação focalizada no "produto", voltando-se para a avaliação do sujeito contextual izado, considerando sua experiência, isto é, seus caminhos perceptuais, seus significados denotativos e conotativos, sua linguagem.

\section{Referências bibliográficas}

AMIRALIAN, M. Lucia T.M. Psicodiagnóstico do cego congênito: aspectos cognitivos. São Paulo, 1986. Dissertação (Mestrado) — Instituto de Psicologia, USP. 
BARRAGA, Natalie. A avaliação educacional do deficiente visual. In: ENCONTRO DE EDUCAÇÃO ESPECIAL, 1, 1983. Anais... São Paulo: FEUSP, 1983.

GOTTESMAN, M. Stage development of blind children: a piagetian. The New Outlook for the Blind, v.70, n.3, p.94-100, 1976.

HALL, Amanda - Mental images and the cognitive development of the congenital I y blind. Journal of Visual Impairement and Blindess, v. 75, n.7, p.281-284, Sept. 1981.

HATWELL, Y. Privation sensorialle et inteligence. Paris: Presses Universitaires de France, 1966.

KAPLAN, A. The conduct of inquiry: methodology for behavioral science. published pursuant to agreement with Chandler Publishing Cia., San Francisco (CA): Chandler Publishing, 1964. . A conduta na pesquisa. São Paulo: EDUSP, 1969.

KAPPERMAN, G. Assesment of the visually handicapped. In: SABATINO, D.A., MILLER, TED. L. (Eds.). Discribing learner characteristics of handicapped children and youth. New York: Grune and Stratton, 1979.

MASINI, E.F.S. O perceber e o relacionarse do deficiente visual: orientando professores especializados. Brasilia: CORDE, 1994.

MAZZOTA, M. J.S. Fundamentos da educação especial. São Paulo: Pioneira, 1981.

MINISTÉRIO DE EDUCAÇÃO E CULTURA. Centro Nacional de Educação Especial. Projeto.Prioritário "Reformulação de Currículos para Educação Especial": proposta curricular para deficientes visuais. Brasília, 1979. v.1. 
SABATINO, D.A., MILLER, TED. L. (Eds). Discribing learner characteristics of handicapped children and youth. New York: Grune and Stratton, 1979.

SWALOW, R. W. Piaget 's theory and the visually handicapped learner,772e New Outlook for the Blind, v. 70, n.3, p.273-280, 1976.

ZAHL, P.A. (Eds.). Blindness: modern approaches to the unseen environment. Princeton (NJ): Princeton University Press, 1950.

Recebido em 3 de abril de 1996.

Elcie F. Salzano Masini, doutora em Psicologia da Educação pela Pontifícia Universidade Católica de São Paulo (PUC/SP), é livre-docente em Educação Especial na Faculdade de Educação da Universidade de São Paulo (USP).

An analysis of the literature concerned with blindness and visually handicapped reveales that research in these fields has been made from a visual point of view. This work considers some of the implications of making evaluations of blind and visually impaired students with the normally sigthted as the reference. It encourages adoptation of evaluation procedures that use the blind or visually impaired student as his own reference.

Une analyse de la bibliographie specialisée sur le déficient visuel a montré que les recherches sur son développement et sur son apprentissage ont été menées d'après les modèles du voyant. Le présent travail, à partir des données de ces recherches, soulève quelques questions afin que ceux qui travaillent avec l'éducation du déficient visuel réfléchissent sur les implications qui découlent de jauger les aveugles et 
les handicapés visuels, en partant du référentiel du voyant; c'est une invitation pour qu'on s'intéresse à trouver des voies pour connaître le déficient visuel en ayant pour source son propre référentiel.

Un análisis de la bibliografía especializada acerca del deficiente visual reveló que los estudios sobre su desarrollo y aprendizaje se hicieron a través de criterios del vidente. Este trabajo, partiendo de los resultados de esta investigación, ofrece algunas conclusiones, para que los que se dedican a educar deficientes visuales las lleven en cuenta en el momento de evaluar los ciegos o los portadores de baja visión utilizando el referencial del vidente. Es una invitación a des cubrir formas de conocer al deficiente visual a través de su propio referencial. 


\section{Anexo}

PESQUISAS SOBRE O DEFICIENTE VISUAL

1. Swalow cita várias pesquisas, comentando que pouco ajudam quem lida com o deficiente visual:

- Referentes à coordenação motora:

- No vidente, a preensão visão-mão ocorre aos 4 meses.

- No cego, a preensão audição-mão ocorre aos 6 meses.

Fraiberg mostra crianças com 5 meses sem problemas quando apropriadamente estimuladas pela mãe.

- Referentes ao desenvolvimento cognitivo:

- Atraso dos cegos na formação das estruturas subjacentes à classificação devido a problema perceptível ou figurativo (simbólico).

Mephart/Mephart e Schwartz pesquisaram o desenvolvimento de imagens visuais através de descrições verbais do meio ambiente.

— Referentes à linguagem:

- Depois dos 8 anos as crianças cegas apresentam atraso em capacidades conceituais (Friedman e Pasnak).

-Atraso no vocabulário (Hopkins e MacGuire, 1964; Tillman, 1967).

2. Gottesman cita várias pesquisas piagetianas que evidenciam o atraso do deficiente visual*: depois vida.

- Canning (1957): crianças cegas adquirem conservação de água

- Hatwell (1966): crianças cegas congênitas ou com cegueira adquirida eram dois a três anos rnais atrasadas que as videntes.

— Miller (1969): estudou a conservação (peso e volume) em crianças de 7 a 10 anos; crianças parcialmente videntes são melhores que com visão.

\footnotetext{
* O deficiente visual apresenta resultados deficitários, segundo Piaget (na Formação do simbolo nas crianças), na imitação e no jogo simbólico. Simbolo para Piaget é uma imagem que serve para traduzir as experiências do indivíduo.
} 
— Simpkins e Stephens (1973) : em tarefas concretas e formação (conservação, classificação, memória, imagem mental, operações formais); crianças cegas têm atraso de quatro a oito anos no desenvolvimento cognitivo.

- Gottesman realiza sua pesquisa:

- Não encontrou diferença entre cegos e videntes e videntes vendados, com sujeitos de 2 a 8 anos.

- Sujeitos cegos do experimento eram bem aceitos pelos familiares, realizavam rotinas domésticas e desfrutavam de bastante liberdade dada pelos pais.

3. Hall cita várias pesquisas evidenciando diferenças entre cego e vidente:

- Hans (1974): diferenças de imagens (visuais e táteis) influem decisivamente na capacidade dos cegos resolverem problemas verbais.

— Fraiberg (Hall, 1981): atraso na intelecção representacional de crianças cegas de 2 a 3 anos quanto ao uso significativo de palavras e suas combinações.

— Foster (Hall, 1981): imagens são basicamente reprodutivas, estáticas e incapazes de antecipar processos (para Piaget, imagens mentais ajudam a formular operações e as limitações afetam o processo cognitivo).

- Carroll e Omwake e Solmitz, Zweibelson e Barg (in Hall, 1981) mostraram que a perda da visão prejudica a organização e a retenção de representações, afetando o pensamento racional.

- Hall retoma os resultados através do referencial de Brunner:

Representações: Inativas $\Rightarrow$ de ação

$$
\text { Icônicas } \quad \Rightarrow \text { de imagens (pictóricas) }
$$

Simbólicas $\Rightarrow$ nominais

E conclui: diferenças de desempenho podem revelar não fraqueza no pensamento, mas que os cegos realizam tarefas que exigem diferentes habilidades cognitivas (representações), apoiando-se em sistemas de representação impróprios para a tarefa. Por exemplo:

Paivio $=>$ Imagens visuais baseadas na comunicação verbal para processar aspectos ligados ao espacial. 
4. Amiralian pesquisa a interferência da cegueira nas diferentes áreas do desenvolvimento cognitiva e busca os procedimentos rnais adequados ao diagnóstico e obtem o seguinte resultado com cegos congênitos:

- No WISC verbal: resultado abaixo da média.

\section{- NoBlat:}

- Resultados rnais altos referentes à manipulação.

- Resultados rnais baixos referentes ao desempenho verbal.

- Resultados melhores referentes: $=>$ identificar, $\Rightarrow$ discriminar, $\Rightarrow$ estabelecer relações.

- Resultados piores nos produtos da aprendizagem. 